\title{
Homogeneous nucleation of sulfuric acid and water mixture: experimental setup and first results
}

\author{
D. Brus ${ }^{1,2}$, A.-P. Hyvärinen ${ }^{2}$, Y. Viisanen ${ }^{2}$, M. Kulmala ${ }^{3}$, and H. Lihavainen ${ }^{2}$ \\ ${ }^{1}$ Laboratory of Aerosol Chemistry and Physics, Institute of Chemical Process Fundamentals Academy of Sciences of the \\ Czech Republic, Rozvojová 135, 16502 Prague 6, Czech Republic \\ ${ }^{2}$ Finnish Meteorological Institute, Erik Palménin aukio 1, P.O. Box 503, 00100 Helsinki, Finland \\ ${ }^{3}$ Department of Physical Sciences, University of Helsinki, P.O. Box 64, 00014 Helsinki, Finland
}

Received: 6 August 2009 - Published in Atmos. Chem. Phys. Discuss.: 11 November 2009

Revised: 10 March 2010 - Accepted: 13 March 2010 - Published: 18 March 2010

\begin{abstract}
In this study we introduce a new flow tube suitable for binary and ternary homogeneous nucleation studies. The production of sulfuric acid and water vapor mixture, the experimental setup and the method of sulfuric acid concentration determination are discussed in detail. Wall losses were estimated from the measured sulfuric acid concentration profiles along the flow tube and compared to a theoretical prediction. In this investigation the experimental evidence of new particle formation was observed at a concentration of $10^{9}$ molecules $\mathrm{cm}^{-3}$ of sulfuric acid and the nucleation rates measured at three relative humidities $(\mathrm{RH}) 10$, 30 and $50 \%$, cover six orders of magnitude, from $10^{-3}$ to $10^{3}$ particles $\mathrm{cm}^{-3}$. Particle free air was used as a carrier gas. Our initial results are compared to the theoretical prediction of binary homogeneous nucleation, to results obtained by other investigators, and to atmospheric nucleation.
\end{abstract}

\section{Introduction}

Aerosol particles in the atmosphere affect the radiative balance of the globe both directly and indirectly (Twomey, 1991 and 1974); thus affecting the global temperature. Aerosols may also cause negative health effects (Davidson et al., 2005) and they can seriously affect visibility. New particle formation in the atmosphere has received considerable attention lately both from atmospheric scientists and aerosol researchers. New particles in the atmosphere have been observed to form by self-condensing, or nucleating homogeneously, in events lasting a few hours across most of the

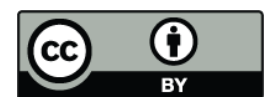

Correspondence to: D. Brus

(brus@icpf.cas.cz) world (Kulmala et al., 2004). This pathway can dramatically increase the local aerosol number concentration (Spracklen et al., 2006).

To understand the mechanism of new particle formation events, considerable work has been done involving direct field and laboratory measurements, as well as computer simulations, both on nucleation itself, and the aerosol dynamics observed during the events. Despite coming closer to drawing conclusions from all available data, exact knowledge of the nucleation event mechanism remains unclear.

The first step of new particle formation or any first order phase transition is nucleation. Vapor to liquid nucleation may occur if the partial pressure of the vapor exceeds its equilibrium vapor pressure in the surrounding conditions. It has been calculated that in the atmosphere the equilibrium vapor pressure of sulfuric acid is low enough for it to be a likely candidate to nucleate homogeneously (Seinfeld and Pandis, 1998). While binary nucleation of sulfuric acid and water may explain nucleation in stratospheric or upper tropospheric temperatures (Clarke et al., 1998; Weber et al., 1999; Vehkamäki et al., 2002), some other substances enhancing nucleation may be needed in the lower troposphere. These compounds are yet to be identified, although ammonia has been suggested as a favorite candidate (Korhonen et al., 1999).

Laboratory experiments on the nucleation of binary sulfuric acid and water date back to 1976 when Reiss et al. measured nucleation rates in a piston cloud chamber. Similar experiments were conducted by Boulaud et al. (1977) in a reactor study, Mirabel and Clavelin (1978) in a thermal diffusion cloud chamber, and Friend et al. (1980) in a laminar flow reactor. More recent experiments include those made by Wyslouzil et al. (1991), Viisanen et al. (1997), Ball et al. (1999), Zhang et al. (2004), Berndt et al. (2006), Benson

Published by Copernicus Publications on behalf of the European Geosciences Union. 
et al. (2008), and Young et al. (2008). All the latter experiments relied on a flow-based measurement technique. Some experimentalists (Friend et al., 1980; Berndt et al., 2006; Benson et al., 2008 and Young et al., 2008) employ photooxidation of $\mathrm{SO}_{2}$ and some produce gaseous mixtures from liquid $\mathrm{H}_{2} \mathrm{SO}_{4}$, using saturators (Wyslouzil et al., 1991 and Ball et al., 1999) or liquid samples (Viisanen et al., 1997). However, it should be pointed out that laboratory measurements are widely conducted at temperatures $10-30^{\circ} \mathrm{C}$ higher than nucleation occurs in the atmosphere. Only a narrow temperature range of $20-30^{\circ} \mathrm{C}$ was utilized in measurements by Wyslouzil et al. (1991) with their plot of nucleation rate vs. relative acidity indicating that a $5{ }^{\circ} \mathrm{C}$ decrease in nucleation temperature would lead to a decrease in nucleation rate of two to four orders in magnitude.

In this work we present a new flow tube (FT) based on a design suggested by Viisanen et al. (1997). The FT is very simple in construction and easy to operate; it is also capable of performing long-lasting experiments with a stable particle production. We show how the concentration of sulfuric acid is measured, and its losses to the wall in the nucleation chamber are estimated. The obtained nucleation rate data are then compared to the binary homogenous nucleation parameterization of Vehkamäki et al. (2002), and experimental data published by others.

\section{Experimental setup}

The flow tube built recently at Finnish Meteorological Institute in Helsinki, Finland is capable of both binary and ternary homogeneous nucleation measurements. The flow tube is positioned vertically and its entire length is about three meters. The experimental setup consists of five main parts: an atomizer, a furnace, a mixing unit, a nucleation chamber and a particle detector unit (see Fig. 1). A liquid solution of known concentration and amount $(0.22 \mathrm{ml} / \mathrm{min})$ is introduced by the HPLC Pump (Waters 515) through a ruby micro-orifice (Bird Precision $-20 \mu \mathrm{m}$ ) together with sheath particle free air (about $4 \mathrm{l} / \mathrm{min}$ ) into the furnace. The dispersion is vaporized in a furnace (Pyrex glass tube) which is $60 \mathrm{~cm}$ long and has an internal diameter (I.D.) of $2.5 \mathrm{~cm}$. The tube is wrapped with resistance heating wires. The temperature inside the furnace is kept at approximately $470 \mathrm{~K}$ and controlled by a PID controller to within $\pm 0.1 \mathrm{~K}$ (DigiTrace, TCONTROL-CONT-02). After the furnace, the vapor is filtered with a Teflon filter (MITEX ${ }^{T M}$ Millipore $5.0 \mu \mathrm{m} \mathrm{LS}$ ) to remove any liquid residue or particulate impurities. The Teflon filter is placed on the perforated Teflon support pad just after the furnace, and before the entrance to the mixing unit. The filtered vapor is then introduced into the mixing unit, made of Teflon, and cooled by turbulent mixing with room temperature particle free air to about $320 \mathrm{~K}$. The flow rate of the mixing air is about $81 / \mathrm{min}$. The mixing unit dimensions are: O.D. $=10 \mathrm{~cm}$, I.D. $=7 \mathrm{~cm}$, height $=6 \mathrm{~cm}$. The

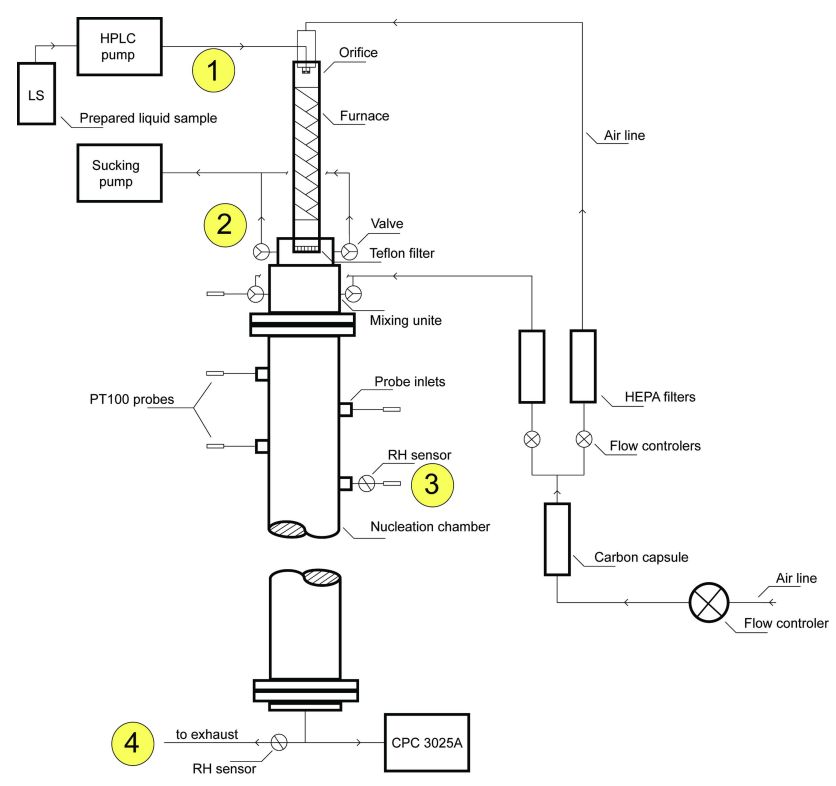

Fig. 1. Schematic of the flow tube. The yellow targets show where: 1) sulfuric acid was sampled from liquid solution. 2, 3 and 4) sulfuric acid was sampled from vapor phase mixture by using bubblers.

mixing unit is kept at room temperature and it is not insulated. Both lines of particle free air (furnace sheath air and mixing air) are controlled by a flow rate controller to within $\pm 3 \%$ (MKS type 250). The vapor gas mixture is then cooled to the desired nucleation temperature in a nucleation chamber, which is kept at a constant temperature (298 K) with two liquid circulating baths (Lauda RK-20). The nucleation chamber is made of stainless steel, with an I.D. of $6 \mathrm{~cm}$ and an entire length of $200 \mathrm{~cm}$. The concentration of water vapor is measured at the centre and far end of the nucleation chamber (see Fig. 1) with two humidity and temperature probes (Vaisala HMP37E and humidity data processor Vaisala HMI38) to within $\pm 3 \%$. The aerosol number concentration is measured just after the nucleation chamber with an ultrafine condensation particle counter (UCPC TSI 3025A).

An optimized procedure of a typical experiment is done in the following way. First we run the experiment with pure water to clean the tube until the particle concentration inside the nucleation chamber drops to 0.5 particles $\mathrm{cm}^{-3}$, which is our background value for pure water. Then, the Teflon filter is swapped for a clean one and autoclaved with hot particle free air at a temperature of $470 \mathrm{~K}$. The autoclaving of the filter is accompanied with a huge particle production which falls exponentially and takes about $12 \mathrm{~h}$. In the next phase, the pure water is used again to flush the tube wall, again the tube is flushed until the particle concentration drops to 0.5 particles $\mathrm{cm}^{-3}$, and consequently, the solution of sulfuric acid and water is made. The series of experiments start at the lowest concentration of sulfuric acid and the highest relative humidity (in our case $\mathrm{RH} \sim 50 \%$ ), and ends at the 


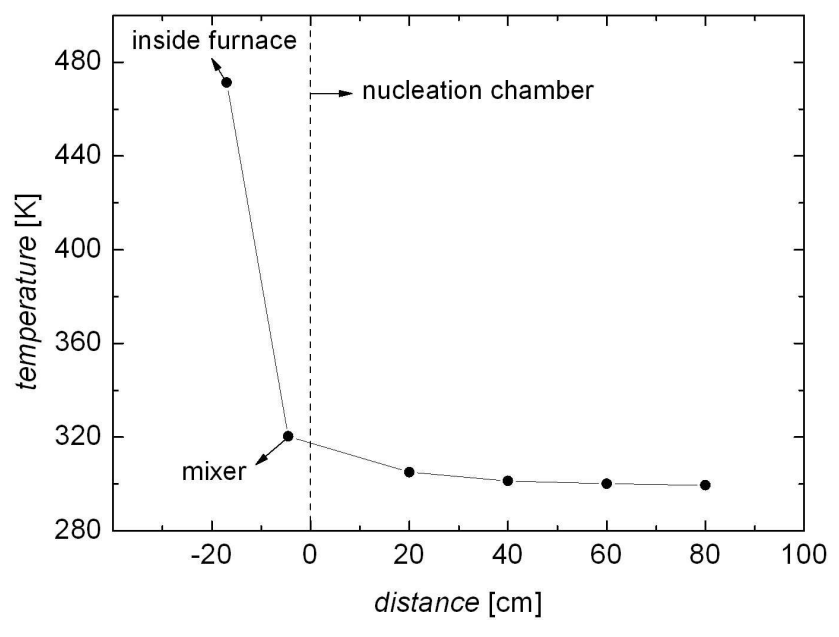

Fig. 2. Measured axial temperature profile inside the nucleation chamber.

highest concentration of sulfuric acid and the lowest relative humidity ( $\mathrm{RH} \sim 10 \%$ ). The concentration of sulfuric acid and water solution in the tube is continuously increased in small steps, i.e. each step means a new solution of sulfuric acid and water. The measurements can be conducted in reverse with lower concentrations of sulfuric acid and water to the previous one, but this usually enormously increases the time necessary for the particle count to settle to the plateau values again.

\subsection{Temperature measurements}

The temperature of the vapor-gas mixture is registered along the flow tube using five PT100 probes. All PT100 probes were calibrated against a standardized thermometer at the Finnish Meteorological Institute to within a standard error of $\pm 0.05 \mathrm{~K}$. The first PT100 probe is immersed into the mixer and the other four are immersed into the nucleation chamber with a distance of $20 \mathrm{~cm}$ from each other, see Fig. 1 for details. The temperature of $298 \mathrm{~K}$ is achieved at a distance of approximately $80 \mathrm{~cm}$ from the beginning of the nucleation chamber; see the axial temperature profile in Fig. 2. The radial temperature profile in the nucleation chamber was also measured by pushing the PT100 probes toward the axis of the chamber with steps of $5 \mathrm{~mm}$ to obtain a good profile resolution. It can be seen on Fig. 3 that, at a distance $20 \mathrm{~cm}$ from the beginning of the nucleation chamber, we obtained a parabolic temperature profile. The radial profile is almost flat at a distance of $80 \mathrm{~cm}$. It should be noted that the temperatures measured close to the axis of the nucleation chamber are slightly influenced by heat conduction along the surface of the PT100 probe. In normal experimental conditions the PT100 probes are immersed so that they create a flat surface together with the inner wall of the nucleation chamber and the bodies of probes are not disturbing the flow inside the chamber.

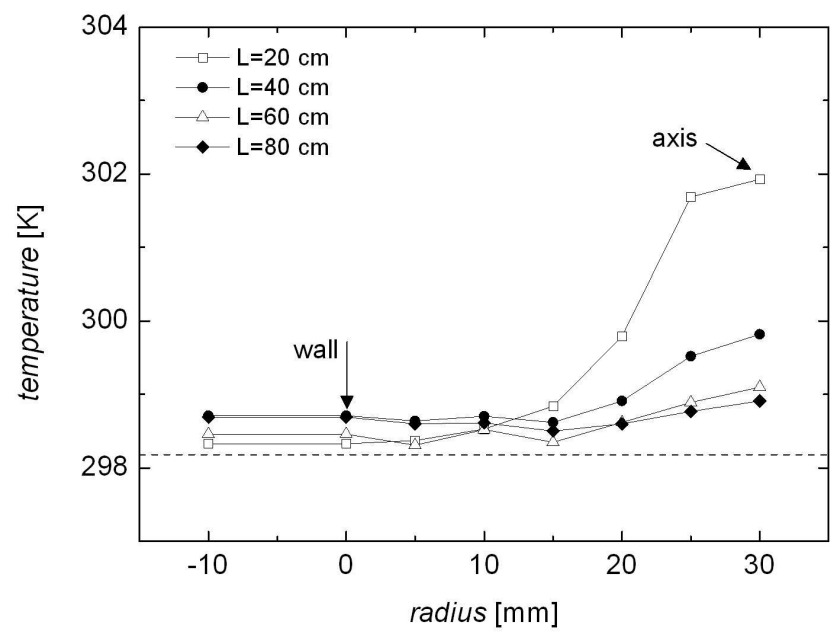

Fig. 3. Measured radial temperature profile inside the nucleation chamber.

\subsection{RH measurements}

The concentration of water vapor in the system can be changed in two ways. Firstly, the flow rate of liquid sample from HPLC pump can be adjusted. Secondly, the water vapor concentration can be altered by sucking the vapor mixture just after the furnace and before the vapor is introduced into the mixer. Both of these approaches have certain limitations.

The optimal value of the HPLC liquid sample flow rate was found to be $0.22 \mathrm{ml} / \mathrm{min}$, which produces a stable jet for long-running experiments. The lower HPLC flow rate usually led to creation of droplets at the micro-orifice and the higher flow rate led to very high values of relative humidity, which puts significant demands on the subsequent sucking section.

In Fig. 4 it can be seen how we can change the relative humidity in the system if we keep the HPLC liquid sample flow rate $(0.22 \mathrm{ml} / \mathrm{min})$ and the two dilution air flow rates constant, and employ a sucking section only in between the furnace and the mixer. The concentration of water vapor is measured in the centre and the end of the nucleation chamber (see Fig. 4) with a humidity data processor Vaisala HMI38 and two Vaisala HMP37E humidity and temperature probes. Both of these measured values of relative humidity differ by less than $3 \%$, which is the declared precision of the sensors by manufacturer. The applicable range of relative humidity with this experimental setup is from 10 to $65 \%$. The value of relative humidity becomes more stable when the sucking flow rate becomes higher.

\subsection{Particle counting and stability}

The aerosol number concentration is measured just after the nucleation chamber with an ultrafine condensation particle 


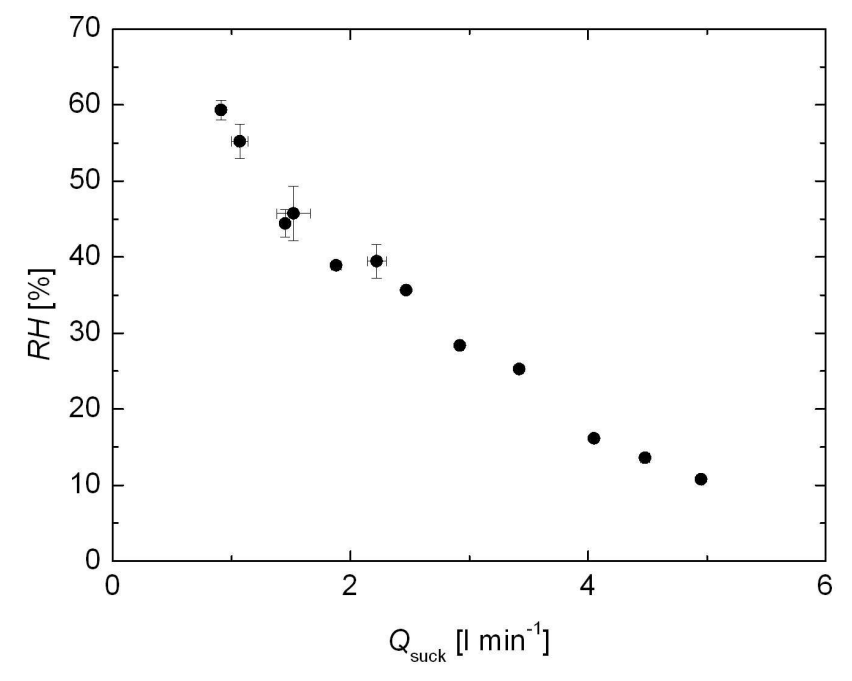

Fig. 4. Relative humidity as a function of flow sucked after furnace measured with pure water. HPLC liquid sample flow rate $(0.22 \mathrm{ml} / \mathrm{l})$ and the two dilution air flow rates are kept constant.

counter (UCPC TSI 3025A), which was calibrated with silver particles to a $\mathrm{d}_{50}$ cut-off of $2.18 \mathrm{~nm}$. The following modification to UCPC TSI $3025 \mathrm{~A}$ has been done to obtain a $\mathrm{d}_{50}$ cut-off of $2.18 \mathrm{~nm}$. The saturator temperature was increased from a nominal $37^{\circ} \mathrm{C}$ up to $38^{\circ} \mathrm{C}$, the condenser temperature was decreased from a nominal $10^{\circ} \mathrm{C}$ down to $8^{\circ} \mathrm{C}$. At these new temperatures no homogeneous nucleation was observed inside the counter. Fig. 5 shows the stability of particle production for three relative humidities (10,30 and 50\%) in long-running (more than $20 \mathrm{~h}$ ) experiments. When the experiment is started the particle production starts to slowly increase, depending on relative humidity, and reaches a certain plateau value in two to three hours. The stable particle production then lasts for many hours with a maximum $\pm 20 \%$ change in the total number concentration per hour.

The flow rate test in Fig. 6 describes what flow rate is the most suitable for our experiments. The flow rate in the nucleation chamber can also be expressed as a residence time, $t$. The particle number concentration $N_{\exp }$ at $50 \%$ of $\mathrm{RH}$ is increasing with increasing residence time in the nucleation chamber until about $60 \mathrm{~s}$, then the particle number concentration $N_{\text {exp }}$ stays constant until $90 \mathrm{~s}$. At a relative humidity of $30 \%$ we see a slight increase in the particle number concentration up to $40 \mathrm{~s}$, and then it starts to decrease with longer residence time.

When we transfer the particle number concentration to nucleation rate $J_{\exp }$ using the simple relationship $J_{\exp }=N_{\exp } / t$, we obtain a different perspective, the maxima of the dependency then shifts closer to lower residence times and the nucleation rate starts to decrease earlier. The decrease is faster at lower relative humidities. The flow in our FT has an optimal residence time from 30 to $45 \mathrm{~s}$; for residence times

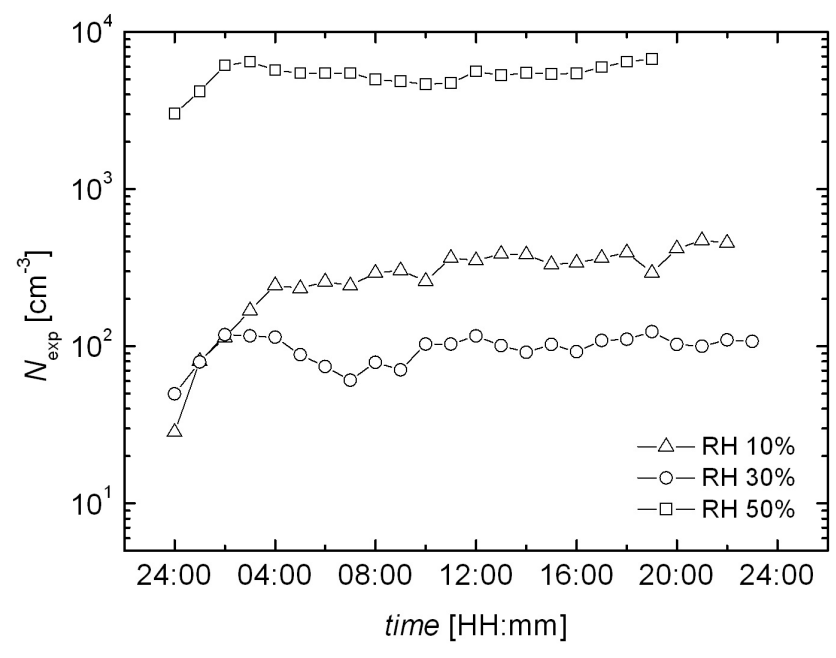

Fig. 5. Experimental total particle number concentration (hourly averages) at three different RHs, 10, 30 and $50 \%$, as a function of time. Measurements were performed at $\mathrm{H}_{2} \mathrm{SO}_{4}$ concentrations of $\mathrm{RH}=10 \%-1.85 \times 10^{10}\left[\mathrm{H}_{2} \mathrm{SO}_{4}\right] \mathrm{cm}^{-3}, \mathrm{RH}=30 \%-2.32 \times 10^{9}$ $\left[\mathrm{H}_{2} \mathrm{SO}_{4}\right] \mathrm{cm}^{-3}, \mathrm{RH}=50 \%-5.01 \times 10^{9}\left[\mathrm{H}_{2} \mathrm{SO}_{4}\right] \mathrm{cm}^{-3}$.

shorter than $30 \mathrm{~s}$ we face undercounting of the UCPC because the most of the particles are not able to grow beyond the detection limit of the UCPC. For residence times longer than $45 \mathrm{~s}$, though, we have to cope with particle and sulfuric acid losses on the nucleation chamber wall.

Complementary measurements of particle size distribution were also undertaken to show how the particle diameter changes with residence time (Fig. 7). To measure size distribution the Differential Mobility Particle Sizer (DMPS with a short HAUKE type DMA and UCPC TSI 3025A) system was used. The DMPS measurements were made using a bipolar diffusion charger ( $\mathrm{Ni}$ 63) to achieve a steady state charge distribution (Liu and Pui, 1974). Charging efficiencies are calculated according to Wiedensohler's parameterization (Wiedensohler, 1988); the charging probability of three nanometer particles is 0.02 and 0.03 for positive and negative charge, respectively. The inversion of raw data obtained from DMPS measurements is applied to obtain the final distributions and total count.

The experiment was performed at three resident times, 30,45 and $90 \mathrm{~s}$, with a $\mathrm{H}_{2} \mathrm{SO}_{4}$ total concentration of $9.84 \times 10^{9}$ molecules $\mathrm{cm}^{-3}$, and a RH of $50 \%$. The particle diameter increases with longer residence times, but, conversely, the total particle concentration decreases (the same behavior was found in the flow rate test experiment, Fig. 6). Particle diameters of 2.2, 2.4 and $2.7 \mathrm{~nm}$ were estimated for residence times of 30,45 and $90 \mathrm{~s}$ respectively. The particle diameter is larger than the UCPC 3025A $(2.18 \mathrm{~nm})$ cut-off for all residence times.

Figure 8 shows the comparison of the integrated particle count obtained from the inversion of the DMPS data and the total particle count measured with the UCPC 3025A. Due 

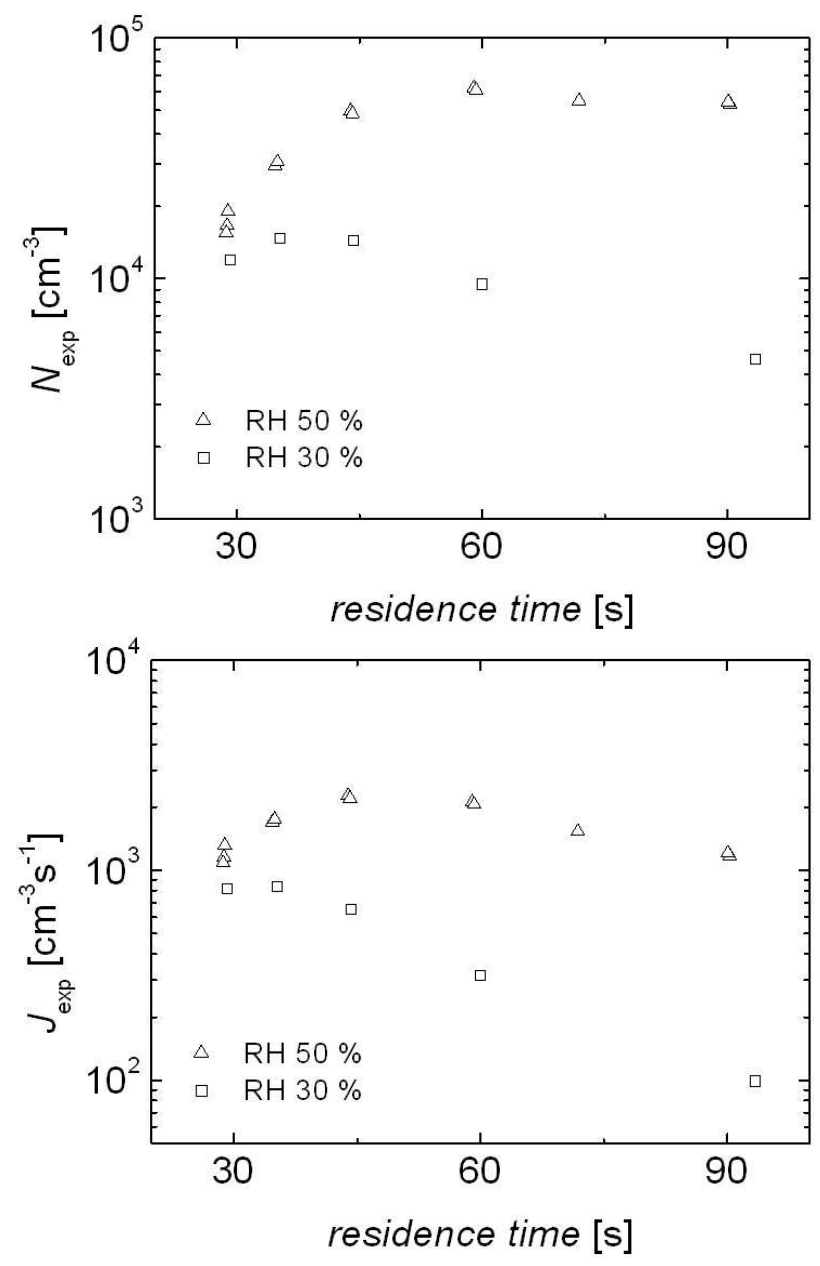

Fig. 6. Particle number concentration $N_{\text {exp }}$ and nucleation rate $J_{\exp }$ as a function of residence time in the nucleation chamber.

to the inversion of DMPS data, the total concentrations are different to those measured with the stand-alone UCPC. The DMPS gives total particle counts which are a factor of 2.8, 2.7 and 1.4 (for residence times 30, 45 and $90 \mathrm{~s}$ ) larger than the total particle count measured by the UCPC 3025A (with counting efficiency and tube losses not taken into account). The particle losses due to diffusion also seem to be higher at the residence time of $90 \mathrm{~s}$ for the inverted DMPS data. The stand-alone UCPC was used to give the particle count data in our measurements as we do not know the exact dependency of particle diameter as function of sulfuric acid concentration, $D_{p}=\mathrm{f}\left(\left[\mathrm{H}_{2} \mathrm{SO}_{4}\right]\right)$ at all measurement conditions. To successfully match the DMPS total count, the counting efficiency of the UCPC TSI 3025A as function of particle size has to be known, which is then dependent on sulfuric acid concentration. The DMPS measurements are performed only for high concentrations of sulfuric acid; at low sulfuric acid concentrations we do not have a sufficient particle number concentration to run the DMPS.

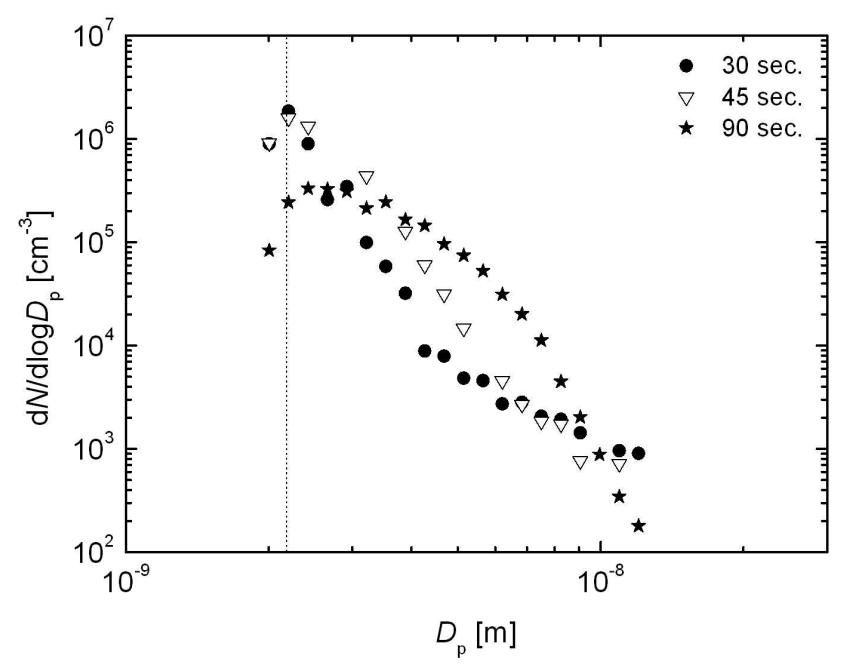

Fig. 7. Particle size distribution (DMPS with a short HAUKE DMA and UCPC TSI 3025A) measured at three resident times 30, 45 and $90 \mathrm{~s}$. Particle diameters were estimated to be $2.2,2.4$ and $2.7 \mathrm{~nm}$, respectively. Measurements were performed at $\mathrm{H}_{2} \mathrm{SO}_{4}$ concentration of $9.84 \times 10^{9}$ molecule $\mathrm{cm}^{-3}$ and RH of $50 \%$. Dotted line represents TSI $3025 \mathrm{~A} d_{50}$ cut-off of $2.18 \mathrm{~nm}$.

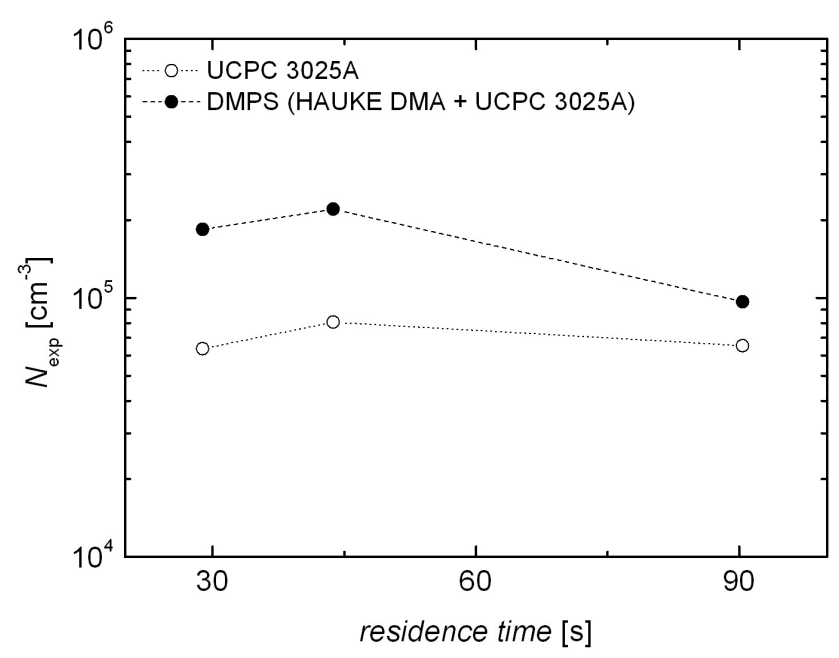

Fig. 8. Integral particle count obtained from inversion of DMPS measurements and total particle count measured with UCPC 3025A as a function of residence time.

\subsection{Nucleation zone determination}

The nucleation zone is the region inside the nucleation chamber where the nucleation takes place. It is very important to determine the region where the nucleation is initiated. It ensures that the nucleation is a homogeneous process independent on any local changes in vapor-gas mixture composition and temperature, especially at the beginning of the nucleation chamber where particles can be spontaneously produced due to rapid changes in temperature alone. The flow profile in our FT is slightly influenced by buoyancy 
driven convection at the beginning of the nucleation chamber. The typical Reynolds (Re) and Grashof ( $\mathrm{Gr}$ ) numbers for $\mathrm{RH}=30 \%$ at three distances along the nucleation chamber are: $\mathrm{Re}=272, \mathrm{Gr}=117141$ at $0 \mathrm{~m} ; \mathrm{Re}=319, \mathrm{Gr}=29635$ at $1 \mathrm{~m}$; and $\mathrm{Re}=478, \mathrm{Gr}=7620$ at $2 \mathrm{~m}$. The laminar flow is fully developed after $50 \mathrm{~cm}$ from the beginning of the nucleation chamber, where the temperature of the vapor-gas mixture starts to reach the temperature of inner surface.

The cut-off of the UCPC 3025A was found unsatisfactory for determining the nucleation zone as the thermodynamically stable clusters (TSC, Kulmala et al., 2007) formed by binary homogeneous nucleation (BHN) of sulfuric acid and water are neutral molecular clusters with mean mobility diameters about $1.5 \mathrm{~nm}$. The Pulse High CPC, which is able to measure particles with diameter about $1.5 \mathrm{~nm}$, was found to be the appropriate device for these measurements. Also, a special probe with 45 degrees cut tip was used. It should be noted that the PH-CPC is a unique device and was used in these measurements for short period of time, only to determine the nucleation zone. The PH-CPC is a modified version of the UCPC 3025A where the laser is changed to a lamp that produces white light. The UCPC 3025A was modified in the following way; the inlet flow of PH-CPC was changed to $1.6 \mathrm{l} / \mathrm{min}$, and the condenser flow to $0.3 \mathrm{l} / \mathrm{min}$ (divided into $\sim 0.06 \mathrm{l} / \mathrm{min}$ - sample $/ 0.24 \mathrm{l} / \mathrm{min}$ - sheath). The saturator temperature was increased from the nominal $37^{\circ} \mathrm{C}$ to $43^{\circ} \mathrm{C}$. The condenser temperature was kept at $10^{\circ} \mathrm{C}$ to yield the maximum saturation ratio of $S \approx 4.0$ (in default setting, $S \approx 3.1$ ).

The multi channel analyzer (MCA) is attached inside the $\mathrm{PH}-\mathrm{CPC}$ and measures the amount of scattered, which is proportional to the size of the measured particles. The main disadvantage associated with the PH-CPC is that the particle concentration cannot be too high, i.e. the experiment has to be carried out at low concentrations of sulfuric acid. If more than one particle enters the optics at the same time, the MCA may detect them as one large particle overestimate the size. Also, if the detector has just detected a particle, it will be offline for certain time (orders of milliseconds) and cannot detect a new particle; in this case the concentration may be underestimated. The detailed principle of operation and more technical details about the PH-CPC can be found in Sipilä et al. (2008).

To obtain the position of the nucleation zone the particle concentration was measured in a similar manner to the temperature profile inside the nucleation chamber. The probe was pushed from the wall inner surface towards the axis of the chamber in steps of $1 \mathrm{~cm}$ to obtain the particle concentration profile in the nucleation chamber. The measurements were repeated for each hole at four different distances (20, 40,60 and $80 \mathrm{~cm}$ ) along the nucleation chamber, with one additional measurement at the end of the tube to obtain the total particle concentration. Figure 9 shows the particle number concentration for two residence times ( 30 and $45 \mathrm{~s}$ ) along the axis of the nucleation chamber. Residence times of 30

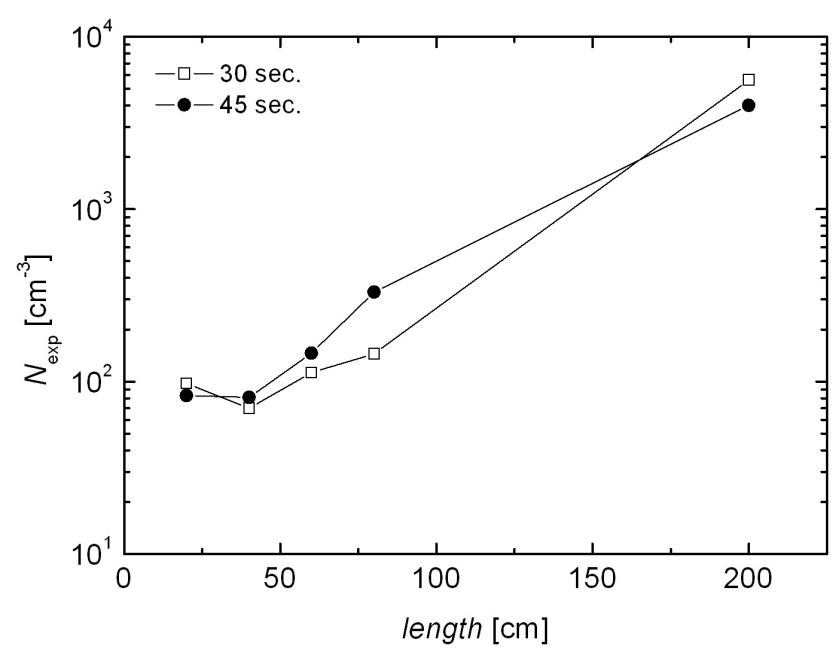

Fig. 9. Nucleation zone measured at the axes of the nucleation chamber, particle concentration measured with PHCPC at RH $30 \%$ and total concentration of $5.78 \times 10^{9} \mathrm{H}_{2} \mathrm{SO}_{4}$ molecules $\mathrm{cm}^{-3}$. The open symbols are measured at residence time of $30 \mathrm{~s}$ and solid symbols at residence time of $45 \mathrm{~s}$.

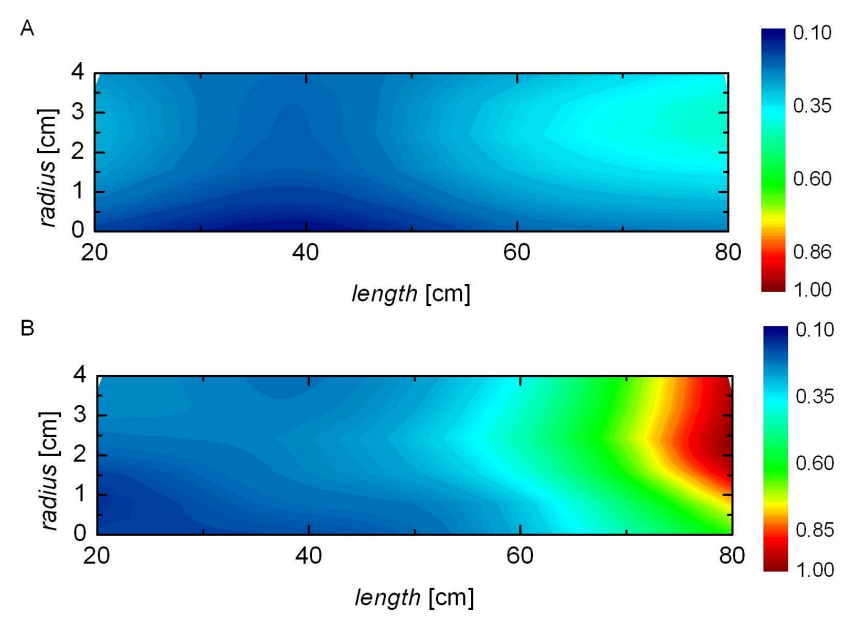

Fig. 10. Normalized total particle number concentration measured with $\mathrm{PH}-\mathrm{CPC}$ at $\mathrm{RH} 30 \%$ and total concentration of $5.78 \times 10^{9}$ $\mathrm{H}_{2} \mathrm{SO}_{4}$ molecules $\mathrm{cm}^{-3}$. (A) Residence time $=30 \mathrm{~s}$ and (B) residence time $=45 \mathrm{~s}$. Radius $=0 \mathrm{~cm}$ refers to the wall, radius $=3 \mathrm{~cm}$ refers to axis.

and $45 \mathrm{~s}$ are calculated for the whole length of nucleation chamber. It is clear that at $20 \mathrm{~cm}$ into the nucleation chamber only about one per cent of the total count at the end of the nucleation chamber is present and means that there is no significant particle production caused by a rapid change in temperature in the mixing unit.

Figure 10 shows the total particle number concentration normalized to the same scale for both residence times ( 30 and $45 \mathrm{~s}$ ) as a function of the radius and the distance from the beginning of the nucleation chamber. This figure should be taken as a qualitative because the raw data have been 
interpolated and normalized. It appears as though there is some slight turbulent mixing for the residence time of $30 \mathrm{~s}$ (Fig. 10a) at the beginning of the nucleation chamber compared to residence time of $45 \mathrm{~s}$ (Fig. 10b) where the particle production seems to be much smoother.

The raw total particle number concentration measured by the PH-CPC is presented in Fig. 11 for different distances along the nucleation chamber as a function of radius. The nucleation zone peak starts around $70 \mathrm{~cm}$ from the beginning of nucleation chamber for both residence times and we estimate that the maxima are located somewhere close to $1 \mathrm{~m}$ from the beginning of the nucleation chamber. The estimated distance of $1 \mathrm{~m}$ at which maxima of nucleation zone takes place will be used hereafter for the calculation of the residence time and the subsequent calculation of the nucleation rate.

The nucleation time was then estimated as a distance from the nucleation zone maximum to the end of the tube where they were counted. We expect that we might face undercounting of particles which are not able to grow to detectable size.

\subsection{Preparation of solution, determination of $\mathrm{H}_{2} \mathrm{SO}_{4}$ concentration and wall loses}

The liquid samples of sulfuric acid and water mixture are prepared from a $0.01 \mathrm{M}$ solution of $\mathrm{H}_{2} \mathrm{SO}_{4}$ (Reagecon, AVS purity) and ultrapure water (Millipore, TOC less than $10 \mathrm{ppb}$, resistivity $18.2 \mathrm{M} \Omega . \mathrm{cm} @ 25^{\circ} \mathrm{C}$ ). The desired solution concentration is prepared in two steps of dilution. First, 11 of primary solution of concentration $\left(1.96 \times 10^{-4} \mathrm{~mol} / \mathrm{l}\right)$ is made by adding $20 \mathrm{ml}$ of $0.01 \mathrm{~mol} \mathrm{H}_{2} \mathrm{SO}_{4}$ to 11 of pure water. Then the desired final solution for a particular measurement is made. To cover RH's from 50\% to $10 \%$ we prepare 11 of final solution from $0.5 \mathrm{ml}$ to $70 \mathrm{ml}$ of primary solution. The final solution concentration is then checked by Ion Chromatography with a lower detection limit of $0.02 \mathrm{mg} / \mathrm{l}$ of $\mathrm{SO}_{4}^{-2}$.

For the determination of sulfuric acid concentration in the nucleation chamber we employed the method of trapping $\mathrm{SO}_{4}^{-2}$ ions into $\mathrm{NaOH}$ hydroxide solution using bubblers. The hydroxide solution was prepared in similar way to the solution of sulfuric acid and water. First, a primary solution was made, and then a hydroxide solution was prepared for each particular experiment. The only condition to obey was to keep the hydroxide solution molar concentration in excess of double the molar concentration of sulfuric acid and water solution to be injected into the furnace.

The aim of this experiment was to obtain the concentration profile of sulfuric acid as a function of distance along the flow tube, see Fig. 1 (yellow targets). Several samples were taken and subsequently analyzed by Ion Chromatography method in the analytical laboratory at the Finnish Meteorological Institute. The first sample was taken from the prepared solution to obtain an initial concentration for a Mass Balance calculation; the second sample was obtained from
A

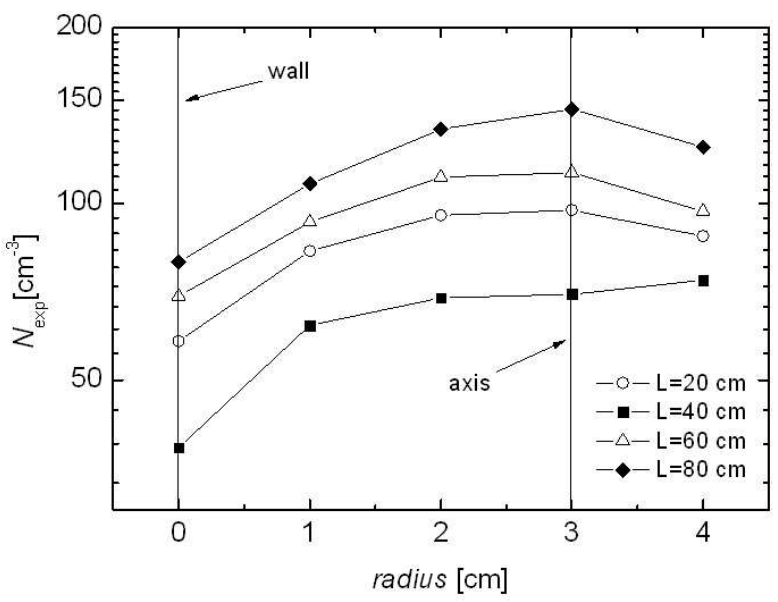

B

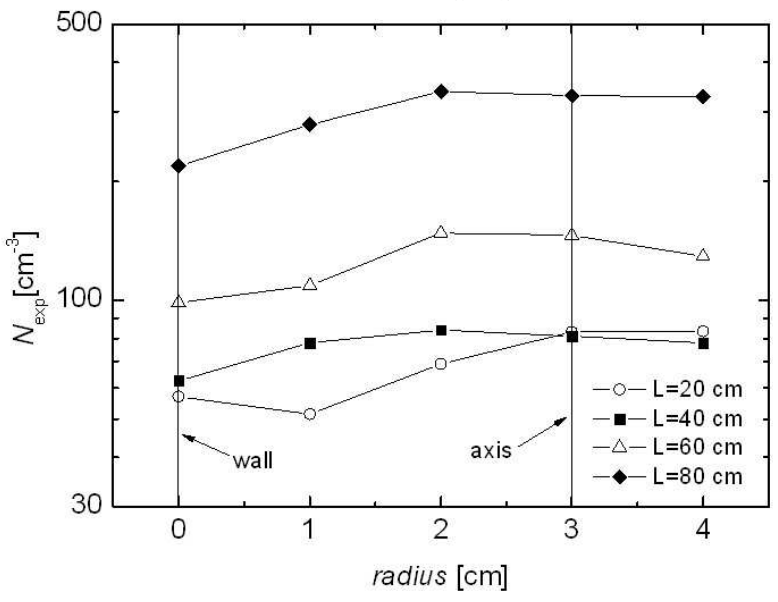

Fig. 11. Total particle number concentration measured with $\mathrm{PH}-$ CPC at different distances along the nucleation chamber as a function of radius, RH $30 \%$ and total concentration of $5.78 \times 10^{9}$ $\mathrm{H}_{2} \mathrm{SO}_{4}$ molecules $\mathrm{cm}^{-3}$. (A) Residence time $=30 \mathrm{~s}$ and (B) residence time $=45 \mathrm{~s}$.

the bubbler positioned at the sucking section just after the furnace, two samples were obtained from two bubblers at a distance of $80 \mathrm{~cm}$ from the beginning of the nucleation chamber, and the two last samples from two bubblers at the end of the nucleation chamber $(200 \mathrm{~cm})$. Each bubbler of the pair at a distance of 80 and $200 \mathrm{~cm}$ was working at a different flow rate (4 and $1.5 \mathrm{l} / \mathrm{min})$ and held different volumes of hydroxide solution $(0.1$ and $0.05 \mathrm{l})$ to crosscheck the obtained concentrations of $\mathrm{SO}_{4}^{-2}$. The resulting concentration of sulfuric acid at which nucleation occurred was then estimated from the average of the concentrations at positions 3 and 4 (at a distance of $140 \mathrm{~cm}$ ), see Fig. 1 . The necessary time for obtaining a detectable amount of $\mathrm{SO}_{4}^{-2}$ (more than $0.02 \mathrm{mg} / \mathrm{l}$ ) was usually longer than $24 \mathrm{~h}$, which demanded a very stable production of particles throughout the whole experiment.

Figure 12 shows the concentration of sulfuric acid determined by Ion Chromatography (IC) as a function of sulfuric acid concentration calculated by Mass Balance (MB): both 


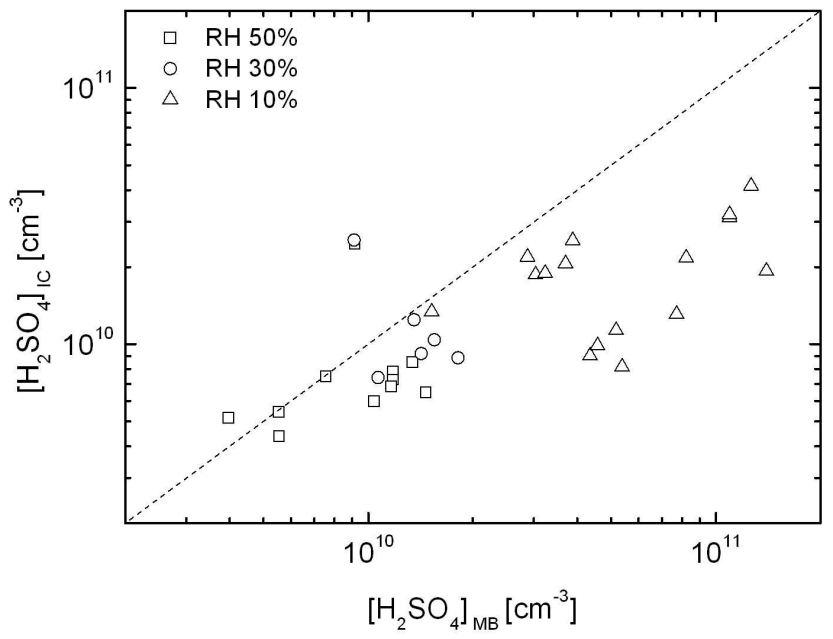

Fig. 12. Concentration of sulfuric acid at three relative humidities determined by Ion Chromatography as a function of sulfuric acid concentration calculated by Mass Balance, both correspond to position 2 in Fig. 1, after the first dilution with particle free air and after furnace. The dashed line represents no losses along the furnace.

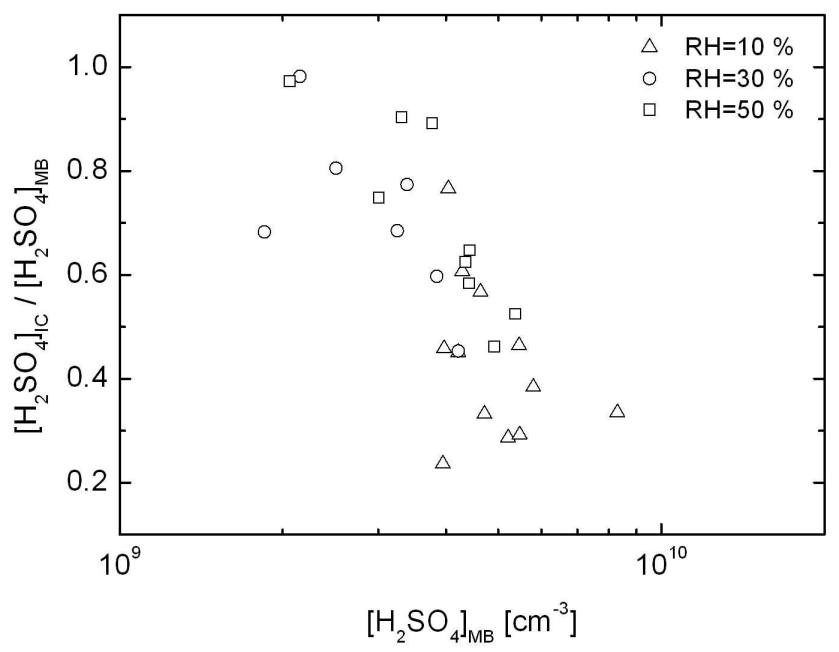

Fig. 13. The ratios of $\mathrm{H}_{2} \mathrm{SO}_{4}$ concentration determined by Ion Chromatography (IC) and initial $\mathrm{H}_{2} \mathrm{SO}_{4}$ concentration calculated by Mass Balance (MB) as a function of initial $\mathrm{H}_{2} \mathrm{SO}_{4}$ concentration calculated by Mass Balance (MB). (A) at $\mathrm{RH}=10 \%$ the average wall losses were estimated to be $54 \%$, (B) at $\mathrm{RH}=30 \%$ the average wall losses were estimated to be $27 \%$, and (C) at $\mathrm{RH}=50 \%$ the average wall losses were estimated to be $28 \%$.

correspond to position 2 on Fig. 1, after the first dilution with particle free air and after the furnace. The dashed line represents no losses along the furnace. The losses of sulfuric acid are higher at a RH of $10 \%$.

Figure 13 shows the ratios of $\mathrm{H}_{2} \mathrm{SO}_{4}$ concentration determined by Ion Chromatography and initial $\mathrm{H}_{2} \mathrm{SO}_{4}$ concentration calculated by Mass Balance as a function of the initial $\mathrm{H}_{2} \mathrm{SO}_{4}$ concentration calculated by Mass Balance. The Mass

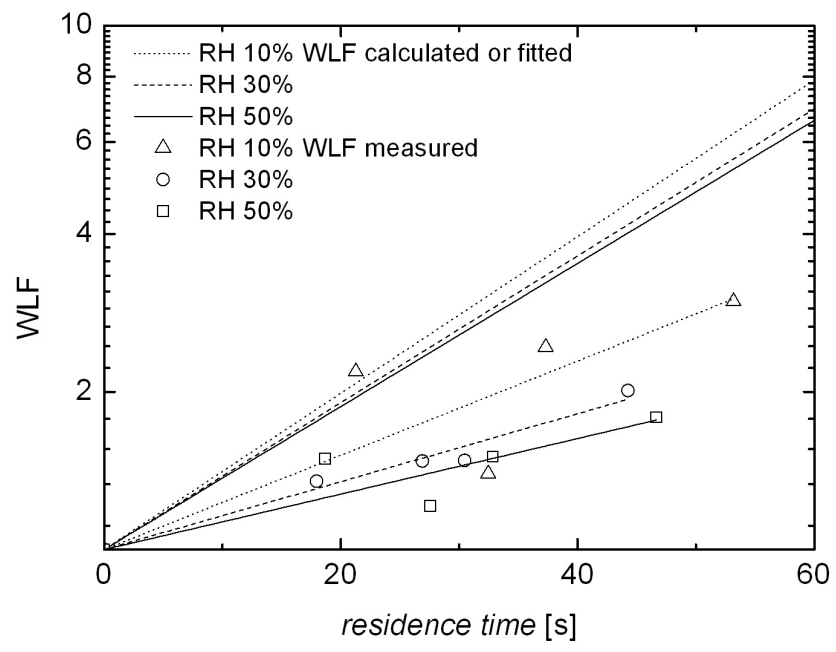

Fig. 14. Wall loss factor as a function of residence time, upper lines are calculated WLFs, points are measured WLFs, lower lines are linear fits to measured values and they correspond to same $\mathrm{RH}$ as calculated lines.

Balance calculation provides a concentration of sulfuric acid at the beginning of the nucleation chamber and does not include any losses connected to diffusion to walls at any part (i.e. at the furnace and the mixing unit). The estimated wall losses for $10 \% \mathrm{RH}$ are about $54 \%$, for $30 \% \mathrm{RH}$ about $27 \%$, and for $50 \%$ RH about $28 \%$. The overall error of the method of sulfuric acid concentration determination was estimated to be $\pm 17 \%$, including the inherent error of Ion Chromatography analysis.

The wall loss factor (WLF) of sulfuric acid can be defined as

$\mathrm{WLF}=\frac{\left[\mathrm{H}_{2} \mathrm{SO}_{4}\right]_{0}}{\left[\mathrm{H}_{2} \mathrm{SO}_{4}\right]_{t}}$,

where $\left[\mathrm{H}_{2} \mathrm{SO}_{4}\right]_{0}$ is the initial concentration of sulfuric acid obtained from Mass Balance calculations, and $\left[\mathrm{H}_{2} \mathrm{SO}_{4}\right]_{t}$ is the concentration of sulfuric acid at residence time, $t$, in the nucleation chamber. Figure 14 shows WLF as function of residence time obtained from bubbler experiments. The expected WLF is included in the figure; this is calculated in the same way as Young et al. (2008) using a RH dependent diffusion coefficient of $\mathrm{H}_{2} \mathrm{SO}_{4}$ in $\mathrm{N}_{2}$ published by Hanson and Eisele (2000). Expected values of the WLF overestimate the WLF obtained from the bubbler experiment by a factor of 2. This is mainly because of two reasons: one, the expected WLFs are calculated with a constant temperature whereas our experiment has a temperature gradient at the beginning of the nucleation chamber, and two; the diffusion of $\mathrm{H}_{2} \mathrm{SO}_{4}$ in air is supposed to be slower than the diffusion of $\mathrm{H}_{2} \mathrm{SO}_{4}$ in $\mathrm{N}_{2}$. The dependency of WLF on RH seems to be more pronounced for measured values, which inherently suggest stronger dependency of diffusion coefficient on $\mathrm{RH}$ 
or a different wall loss mechanism than a first order diffusion limited process.

\section{Results and discussion}

The homogeneous nucleation rates of sulfuric acid and water as a function of sulfuric acid concentration at three different RH's: 10, 30 and 50\% were determined in this study. All experiments were carried out at nucleation temperature of $25^{\circ} \mathrm{C}$. The particle number concentration was measured during the whole experiment but evaluated only for steady state particle production (several hours) and subsequently averaged to obtain only one experimental point. One experimental point also means one solution of sulfuric acid and water. The concentration of sulfuric acid was calculated by Mass Balance and the corresponding losses obtained via bubbler experiment and subsequent Ion Chromatography analyses were applied for each experimental point.

The obtained nucleation rates as a function of concentration of sulfuric acid at constant RH are shown on Fig. 15. The homogeneous nucleation rate data cover about six orders in magnitude from $10^{-3}$ to $10^{3}$ particles $\mathrm{cm}^{-3}$ and the total sulfuric acid concentration ranged from $10^{9}$ to $2 \times 10^{10}$ molecules $\mathrm{cm}^{-3}$ (depending on $\mathrm{RH}$ ). Nucleation rates presented on Fig. 15 should be rather taken as the lowest nucleation rate observable in our system than the real nucleation rates. Firstly, we certainly suffer undercounting of nucleated particles due to the $d_{50}$ cut-off of the UCPC 3025 A, especially at lower concentrations of each RH. Secondly, the counting efficiency was not implemented for the resulting nucleation rates. From our DMPS measurements (Sect. 2.3, Fig. 8) we can see that the inverted DMPS data are about factor of three higher than the total particle count of the UCPC 3025A. Thirdly, we prefer some undercounting of nucleated particles rather than the high losses of sulfuric acid on the wall of the nucleation chamber that would be required for long enough residence times necessary for particles to grow to detectable sizes. We believe that utilizing more efficient counters such as the PH-CPC will reduce this problem in future measurements.

The results are accompanied with a theoretical prediction of binary homogeneous nucleation calculated according to the parameterization suggested by Vehkamäki et al. (2002). This parameterization uses a model for the hydrate formation relying on ab-initio calculations of small sulfuric acid clusters and on experimental data for vapor pressures and equilibrium constants for hydrate formation. The experimental data are about three to four orders of magnitude higher than suggested by the theoretical prediction. The slopes of experimental data are comparable to the theoretical prediction for RHs of 30 and $50 \%$, but shallower at $10 \%$. The linear fit to experimental data suggests about 8,6 , and 4 sulfuric molecules in a critical cluster for RHs of 50, 30 and $10 \%$ respectively. This value is undoubtedly influenced by the un-
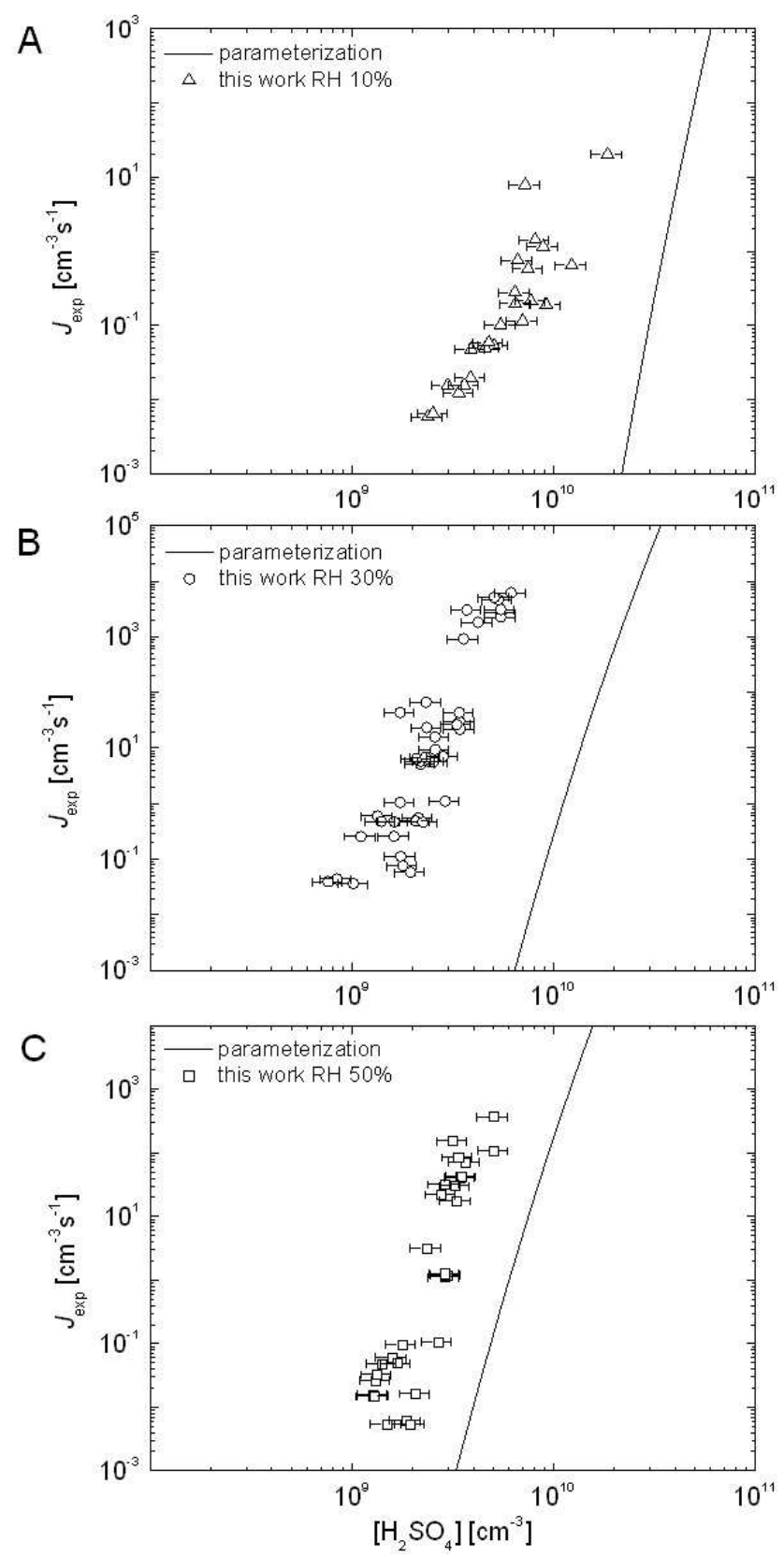

Fig. 15. Nucleation rate as a function of sulfuric acid concentration at three RHs, 10, 30 and 50\%. The error bars correspond to the $17 \%$ uncertainty in the bubbler experiment and subsequent Ion Chromatography analysis. The solid line is the prediction of binary homogeneous nucleation of sulfuric acid and water calculated using the parameterization of Vehkamäki et al. (2002).

dercount of particles at low concentrations of sulfuric acid concentrations due to the $\mathrm{d}_{50}$ cut-off of the UCPC $3025 \mathrm{~A}$. It is necessary to mention that, for the experiments carried out at $\mathrm{RH}=10 \%$, it was very difficult to keep the particle production stable. The FT was very sensitive to any small change in the input parameters (flow rates of sheath and mixing air, temperature of the furnace), which lead to huge changes in 

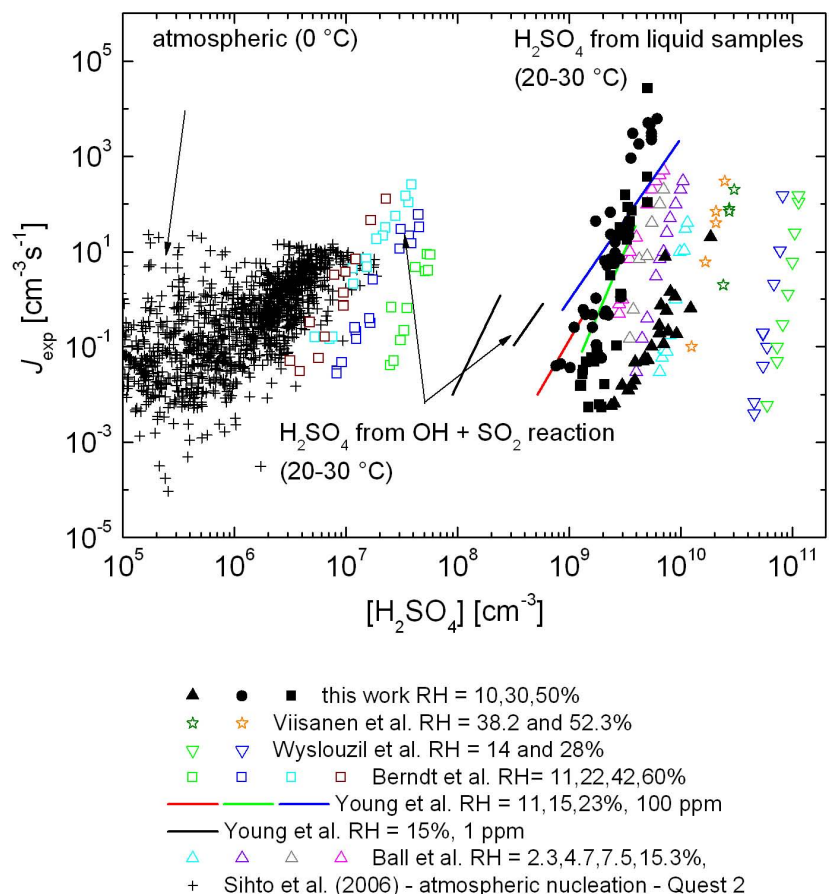

Fig. 16. The comparison of homogeneous nucleation rates as a function of sulfuric acid concentration obtained in this study to data published by other researchers, and to atmospheric nucleation data obtained during the Quest 2 campaign in Hyytiälä, Finland.

particle production, especially at higher nucleation rates (this may explain the shallower slope). The error bars in Fig. 15 stand for uncertainty of the estimated $\mathrm{H}_{2} \mathrm{SO}_{4}$ concentrations from the bubbler experiments $( \pm 17 \%)$.

\subsection{Comparison to experimental data of other researchers, and to atmospheric nucleation}

The experimental data of this work are compared in Fig. 16 to data obtained by other researchers, and to atmospheric nucleation data obtained during the Quest 2 campaign in Hyytiälä, Finland (Sihto et al., 2006). In this investigation the experimental evidence of new particle formation was observed at about $10^{9}$ molecules $\mathrm{cm}^{-3}$ of sulfuric acid, which is directly comparable to new particle formation observed in the studies of Ball et al. (1999) and Young et al. (2008) even though the RH in their studies was about a factor of 2 lower. Viisanen et al. (1997) used a similar experimental setup with comparable RHs but their data lies at about one order of sulfuric acid concentration higher. The wall losses of $40 \%$ estimated in Viisanen et al. (1997) are comparable to the wall losses estimated in this work by bubbler experiments. We expect that the difference between the data presented by $\mathrm{Vi}$ isanen et al. (1997) and our results arises mostly from the different counting efficiencies of the devices used for measuring particle concentration. Similar conclusions could be stated for the data presented in Wyslouzil et al. (1991). The data in Berndt et al. (2006) were originally published in terms of $N_{\exp }=f\left(\left[\mathrm{H}_{2} \mathrm{SO}_{4}\right]\right)$ and to obtain nucleation rates, $J_{\text {exp }}$, we divided the original dataset by a residence time of $290 \mathrm{~s}$. Their data then show experimental evidence of new particle formation for in situ produced $\mathrm{H}_{2} \mathrm{SO}_{4}$ at about $10^{7}$ molecules $\mathrm{cm}^{-3}$. Atmospheric nucleation data are not directly comparable to any laboratory studies at the present time, they are included to provide a complete overview. The mean temperature of atmospheric nucleation data is about $0{ }^{\circ} \mathrm{C}$, the range of $\mathrm{RH}$ is from 30 to $95 \%$ and the nucleation rate is determined for nucleated particles with a diameter of $1.5 \mathrm{~nm}$.

\section{Conclusions}

A new flow tube capable of binary and ternary nucleation measurements, its experimental setup and basic functionality has been presented, including detailed axial and radial profiles of temperature, and the means of regulating $\mathrm{RH}$. The procedure for preparing the sulfuric acid solution and the determination of sulfuric concentration in the nucleation chamber were discussed. The wall losses of 54\%, 27\%, and $28 \%$ were estimated from the bubbler experiments for three $\mathrm{RHs}, 10,30$, and $50 \%$, respectively, with the estimated error of $17 \%$. The stability of particle production during longlasting experiments was demonstrated and the optimal residence times for the nucleation experiments were found to be in the range 30 to $45 \mathrm{~s}$ (for the whole nucleation chamber). The measurements of the nucleation zone using PH-CPCs showed that the peak of new particle production is located about 100 centimeters from the beginning of the nucleation chamber.

Generally, the strategy of rather slight undercounting of nucleated particles due to insufficient growth times was preferred over higher losses of sulfuric acid to the nucleation chamber wall due to long residence times. The experimental evidence of new particle formation was observed at about $10^{9}$ molecules $\mathrm{cm}^{-3}$ of sulfuric acid, which is in good agreement with previously published laboratory studies. The nucleation rates were obtained from the total number particle count divided by the residence time from the nucleation zone peak to the end of the chamber. The obtained nucleation rates cover six orders in magnitude and they range from $10^{-3}$ to $10^{3}$ particles $\mathrm{cm}^{-3}$. The experimental data are about three to four orders of magnitude higher than the parameterization of BHN (Vehkamäki et al., 2002). There is good agreement with previously published data from other researchers, but the concentration of sulfuric acid necessary for new particle formation is still several orders higher than observed in atmospheric measurements.

Acknowledgements. D. Brus would like to acknowledge the KONE foundation (personal grant \# 2-1253) for the support of this research, the EUCAARI (The European Integrated project on Aerosol Cloud Climate and Air Quality Interactions) and 
FCoE (Finnish Center of Excellence of Academy of Finland Physics, Chemistry and Biology of Atmospheric Composition and Climate Change) projects are also gratefully acknowledged for their financial support. Mikko Sipilä and Kimmo Neitola are acknowledged for data analyses and measurements with PH-CPC.

Edited by: J. B. Burkholder

\section{References}

Ball, S. M., Hanson, D. R., Eisele, F. L., and McMurry, P. H.: Laboratory studies of particle nucleation: Initial results for $\mathrm{H}_{2} \mathrm{SO}_{4}$, $\mathrm{H}_{2} \mathrm{O}$, and $\mathrm{NH}_{3}$ vapors., J. Geophys. Res., 104(D19), 2370923718, 1999.

Benson, D. R., Young, L. H., Kameel, F. R., and Lee, S.-H.: Laboratory-measured nucleation rates of sulfuric acid and water binary homogeneous nucleation from the $\mathrm{SO}_{2}+\mathrm{OH}$ reaction, Geophys. Res. Lett., 35, L11801, doi:10.1029/2008GL033387, 2008.

Berndt, T., Böge, O., and Stratmann, F.: Formation of atmospheric $\mathrm{H}_{2} \mathrm{SO}_{4} / \mathrm{H}_{2} \mathrm{O}$ particles in the absence of organics: A laboratory study, Geophys. Res. Lett., 33, L15817, doi:10.1029/2006GL026660, 2006.

Boulaud, D., Madelaine, G., Vigla, D., and Bricard, J.: Experimental study on the nucleation of water vapor sulphuric acid binary system, J. Chem. Phys. 66, 4854-4860, 1977.

Clarke, A. D., Varner, J. L., Eisele, F., Mauldin, R. L., Tanner, D., and Litchy, M.: Particle production in the remote marine atmosphere: Cloud outflow and subsidence during ACE 1, J. Geophys. Res., 103(D13), 16397-16409, 1998.

Davidson, C. I., Phalen, R. F., and Solomon, P. A.: Airborne particulate matter and human health: A review, Aerosol Sci. Tech. 39, 737-749, 2005.

Friend, J. P., Barnes, R. A., and Vasta, R. M.: Nucleation by free radicals from the photooxidation of sulfur dioxide in air, J. Phys. Chem. 84, 2423-2436, 1980.

Hanson, D. R. and Eisele, F.: Diffusion of $\mathrm{H}_{2} \mathrm{SO}_{4}$ in humidified nitrogen: Hydrated $\mathrm{H}_{2} \mathrm{SO}_{4}$, J. Phys. Chem. A, 104, 1715-1719, 2000.

Kulmala, M., Vehkamäki, H., Petäjä, T., Dal Maso, M., Lauri, A., Kerminen, V.-M., Birmili, W., and McMurry, P. H.: Formation and growth rates of ultrafine atmospheric particles: a review of observations, J. Aerosol Sci., 35, 143-176, 2004.

Kulmala, M., Riipinen, I., Sipilä, M., Manninen, H. E., Petäjä, T., Junninen, H., Dal Maso, M., Mordas, G., Mirme, A., Vana, M., Hirsikko, A., Laakso, L., Harrison, R. M., Hanson, I., Leung, C., Lehtinen, K. E. J., and Kerminen, V.-M.: Towards direct measurement of atmospheric nucleation. Science, 318, 89-92, doi:10.1126/science.1144124, 2007.

Liu, B. Y. H. and Pui, D. Y. H.: Electrical neutralization of aerosol, J. Aerosol Sci., 5, 465-472, 1974.

Mirabel, P. and Clavelin, J. L.: Experimental study of nucleation in binary mixtures: The nitric acid-water and sulphuric acid-water systems, J. Chem. Phys., 68, 5020-5027, 1978.

Reiss, H., Margolese, D. I., and Schelling, F. J.: Experimental study of nucleation in vapor mixtures of sulphuric acid and water, $\mathbf{J}$. Colloid Interface Sci. 56, 511-526, 1976.
Seinfeld, J. H. and Pandis, S. N.: Atmospheric Chemistry and Physics: From air pollution to climate change, Wiley, New York, USA, 464-470., 1998.

Sihto, S.-L., Kulmala, M., Kerminen, V.-M., Dal Maso, M., Petäjä, T., Riipinen, I., Korhonen, H., Arnold, F., Janson, R., Boy, M., Laaksonen, A., and Lehtinen, K. E. J.: Atmospheric sulphuric acid and aerosol formation: implications from atmospheric measurements for nucleation and early growth mechanisms, Atmos. Chem. Phys. 6, 4079-4091, 2006.

Sipilä, M., Lehtipalo, K., Kulmala, M., Petäjä, T., Junninen, H., Aalto, P. P., Manninen, H. E., Kyrö, E.-M., Asmi, E., Riipinen, I., Curtius, J., Kürten, A., Borrmann, S., and O’Dowd, C. D.: Applicability of condensation particle counters to measure atmospheric clusters, Atmos. Chem. Phys., 8, 4049-4060, 2008, http://www.atmos-chem-phys.net/8/4049/2008/.

Spracklen, D. V., Carslaw, K. S., Kulmala, M., Kerminen, V.-M., Mann, G. W., and Sihto, S.-L.: The contribution of boundary layer nucleation events to total particle concentrations on regional and global scales, Atmos. Chem. Phys., 6, 5631-5648, 2006, http://www.atmos-chem-phys.net/6/5631/2006/.

Twomey A.: Pollution and the planetary albedo, Atmos. Environ. 8, 1251-1256, 1974.

Twomey S.: Aerosols, clouds and radiation, Atmos. Environ. 25A, 2435-2442, 1991.

Vehkamäki, H., Kulmala, M., Napari, I., Lehtinen, K. E. J., Timmreck, C., Noppel M., and Laaksonen, A.: An improved parameterization for sulfuric acid-water nucleation rates for tropospheric and stratospheric conditions, J. Geophys. Res., 107(D22), 4622, doi:10.1029/2002JD002184, 2002.

Viisanen, Y., Kulmala, M., and Laaksonen, A.: Experiments on gasliquid nucleation of sulphuric acid and water, J. Chem. Phys. 107, 920-926, 1997.

Wiedensohler, A.: An approximation of the bipolar charge distribution for particles in submicron size range, J. Aerosol Sci., 19, 387-389, 1988.

Weber, R. J., McMurry, P. H., Mauldin III, R. L., Tanner, D. J., Eisele, F. L., Clarke, A. D., and Kapustin, V. N.: New particle formation in the remote troposphere: A comparison of observations at various sites, Geophys. Res. Lett., 26(3), 307-310, 1999.

Wyslouzil, B. E., Sienfeld, J. H., Flagan, R. C., and Okuyama, K.: Binary nucleation in acid-water systems. II. Sulphuric acid-water and a comparison with methanesulphonic acid-water, J. Chem. Phys., 94, 6842-6850, 1991.

Young, L. H., Benson, D. R., Kameel. F. R., Pierce, J. R., Junninen, H., Kulmala, M., and Lee, S.-H.: Laboratory studies of $\mathrm{H}_{2} \mathrm{SO}_{4} / \mathrm{H}_{2} \mathrm{O}$ binary homogeneous nucleation from the $\mathrm{SO}_{2}+\mathrm{OH}$ reaction: evaluation of the experimental setup and preliminary results, Atmos. Chem. Phys., 8, 4997-5016, 2008, http://www.atmos-chem-phys.net/8/4997/2008/.

Zhang, R., Suh, I., Zhao, J., Zhang, D., Fortner, E. C., Tie, X., Molina, L. T., and Molina, M. J.: Atmospheric new particle formation enhanced by organic acids, Science 304, 1487-1490, 2004. 